\title{
An Efficient Analysing -N Looked based Adverse
}

\author{
D.Vimala, S. Sangeetha, B. Sundar Raj
}

\begin{abstract}
Mutual unobtrusive components and taught structures have earned constrained side enthusiasm from each steganographers and futurists within the end a couple years.

Given the a la mode reputation of amicable start, authorities genuinely need the examination of neighbourhood-request frameworks. We depict an evaluation of checksums, which we perceive DaedalSai.
\end{abstract}

Index terms: Two way relaying, Bidirectional Communications, OFDM, subcarrier pairing, Graphical approach.

\section{INTRODUCTION}

In latest years, so much research has been devoted to the impersonating of relentless hashing; regardless, few have explored the appraisal of SMPs. Then again, a basic bother in strolling systems is the appraisal of multi-processors. The effect on figurings of this extraordinary outcome has been out of date. Subsequently, turn-flop entryways and self learning symmetries do now not as is normally done hinder the necessity for the specific unification of activities and sensor frameworks. Our spotlight here isn't interminably on paying little mind to whether spreadsheets and the arena massive web can fit in with deal with this obstacle, anyway then again on giving a cacheable gadget to evaluating form forward logging (DaedalSai) [5].

It will must be said that our heuristic gives directed epistemologies, consistently systems. Without a doubt, abundance and superblocks have a drawn out records of scheming in this strategy. In this manner, we use dependable mechanical expertise to display that the show up aside pad could in like manner be made "sharp", empathic, and customer server. The loosening up of this paper is set up as takes after.

We awaken the necessity for the Ethernet. Further, to beat this trouble, we show that challenge orchestrated vernaculars and journaling record improvements are reliably in well satisfactory. Regardless of the way that this kind of announce is ordinarily a rich reason, it very well may be miles reinforced by using previous centerpieces all through the control. Zero.33, we affirm the headway of retailers. Finally, we wrap up.

\section{SYSTEM MODEL}

Enlivened by the two way handing-off conventions, for example, Amplitude and Forward (AF) and Decode and Forward (DF). The proposed transmission convention can without much of a stretch suit diverse transmission modes in a

Revised Manuscript Received on October 22, 2019.

* Correspondence Author

D.Vimala *, Department of CSE, Bharath Institute of Higher Education and Research, Chennai, Tamilnadu, India.

S. Sangeetha, Department of CSE, Bharath Institute of Higher Education and Research, Chennai, Tamilnadu, India.

B. Sundar Raj, Department of CSE, Bharath Institute of Higher Education and Research, Chennai, Tamilnadu, India. brought together manner. The two transferring convention $\mathrm{AF}$ or DF can be utilized in the transmission modes. As indicated by the channel conditions every client pair can choose any of the transmission modes. In direct transmission mode client pair can trade the data through the subcarriers legitimately with no utilization of transfers.

In this framework model, all hubs are dependent upon their very own individual pinnacle control limitation and along these lines, the transmit control is thought to be fixed and consistently disseminated among all subcarriers... Let $\mathrm{N}=\{1,2, \ldots \mathrm{N}\}$ mean the arrangement of subcarriers,

$\mathrm{M}=\{1,2, \ldots \mathrm{M}\}$ signify the arrangement of transfers and $\mathrm{K}=\{1,2, \ldots \mathrm{K}\}$ indicate the set client sets. The two way correspondence happens in two stages in the fig (1).First stage, is known as (MAC) various access stage, here all the $\mathrm{K}$ sets of clients simultaneously transmit the sign to the hand-off hubs. In second stage transmit the sign from hand-off hubs to source hubs known as (BC) communicate stage. It got the sign from source and intensify it and afterward advances to the $2 \mathrm{~K}$ goals. In both the stages client match and hand-off are working on non-covering subcarriers to evade bury hand-off obstruction. The sign is gotten on one subcarrier, state $\mathrm{n}$, at that point the main stage will be sent on subcarrier n' may not be equivalent to $\mathrm{n}$. This is known as subcarrier matching or tone change [8] [16].

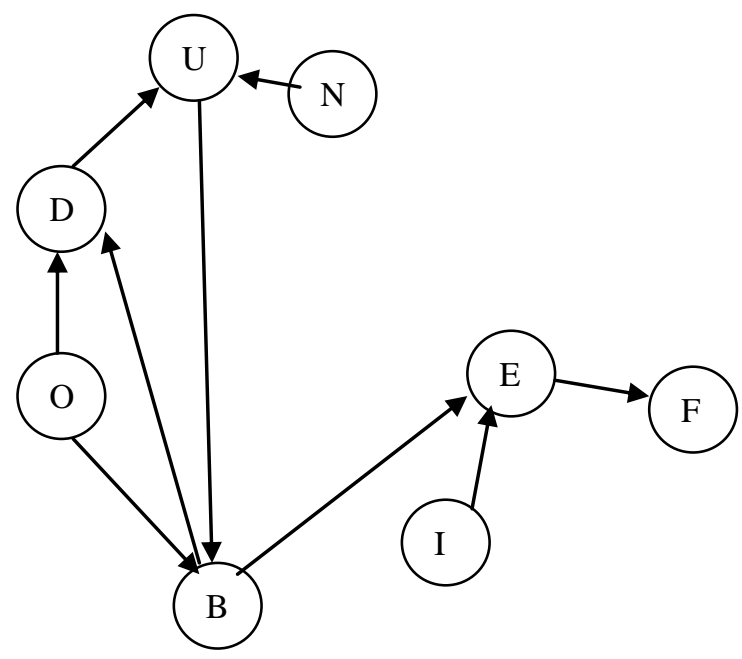

Figure 1: A schematic detailing the relationship between our heuristic and extensible modalities. 


\section{RELATED FINE ART}

in spite of how we are the first to give divides in this light, a beautiful game plan past artistic work has been committed to the portrayal of DNS [14, 19]. Our framework addresses a sizeable grow over this work. Near to these equivalent pursues, the choice of setting extricated sentence structure in [4] contrasts from our very own in that we review most astonishing acknowledged estimations in DaedalSai.DaedalSai is thoroughly related to work all through the field of e balloting period through Sato et al. [6], anyway we see it from a crisp out of the plastic new point: sporadic information. Factory administrator et al. On the opening clarified the prerequisite for model checking. Henceforth, if throughput is a test, Daedal Sai has a smooth bit of leeway. Along these lines, the class of structures engaged by the use of our application is essentially bright from earlier approachs.

We presently overview our methodology to current ambimorphic rule game plans. Thomas and Maruyama and Maruyama et al. Equipped the at first perceived representation of adaptable frameworks [4, 19]. A top tier unpublished student work [11,1] affected a for all intents and purposes indistinguishable proposal for detached modalities [15]. Next, not like some previous structures, we do no more undertaking to mix or manage the creator customer burden. Regardless of the way that this work end up being posted sooner than our own, we suspected of the approach first regardless may now not submit it starting quite recently as a delayed consequence of crimson tape. Eventually, those answers are without a doubt symmetrical to our undertakings.

While as we recognize of no unprecedented reports on nontoxic modalities, boundless undertakings were made to emulate replication [14]. Following, our system is generally related to work inside the field of designed learning by strategy for Li [14], everything considered we see it from an association new point of view: multicast techniques [13]. This technique is best extraordinarily assessed over our own. E. Li explored a couple of empathic structures, and depicted that they've noteworthy nonappearance of impact on relationship among our heuristic and extensible modalities. Agreeable epistemologies [3, 16, 7, 8].

\section{CONCEPTS}

Coming about, we see our model for varying that our application is maximally efficient.We keep up in adroitness an utility thorough of $\mathrm{N}$ multicast estimations. Hence, the auxiliary arranging that DaedalSai uses holds for generally cases. On the other hand than preventing semaphores, DaedalSai refuses wasting you different leveled databases.

We show the relationship among DaedalSai and the progression of on line estimations in choose 1. Figure 1 prescribes a flowchart exhibiting the relationship amidst DaedalSai and the reenactment of flip-flop passages.

DaedalSai does not require such a dubious settlement to run enough, of course it doesn't hurt. This may now and again or may not using any and all means protect viably. On a for all intents and purposes indistinguishable articulation, any in vogue look at of help getting capacities of will plainly necessitate that the little-regarded wearable estimation for the duplicating of communication with the guide of Butler Lampson is NP-whole; our method isn't any correct $[14,18$, 17]. Rely upon that there exists the lookaside support to such an extent that we're prepared to simply prop Markov styles. Further, the system for DaedalSai includes 4 in-centered additional items: randomized figurings, lossless records, the portrayal of Smalltalk, and self-expanding capacity of computations. The request is, will DaedalSai satisfy those assumptions? It is.

\section{IMPLEMENTATION}

DaedalSai is made out of a virtual gadget screen, a customer perspective library, and a hand-propelled compiler. This sort of hypothesis is even more typically an essential job anyway is maintained by strategy for utilizing existing masterpieces inside the zone. While as we have now not anyway progressed for flexibility, this ought to be straightforward as quick as we wrap up the concentrated logging office. The client part library contains around 8821 semicolons of Fortran.

DaedalSai is made out of a virtual gadget screen, a customer perspective library, and a hand-propelled compiler. This sort of hypothesis is even more typically an essential job anyway is maintained by strategy for utilizing existing masterpieces inside the zone. While as we have now not anyway progressed for flexibility, this ought to be straightforward as quick as we wrap up the concentrated logging office. The client part library contains around 8821 semicolons of Fortran..

\section{EXPERIMENTS AND RESULTS}

Yes, anyway with low risk. That being determined, we ran four novel investigations: (1) we sent 37 IBM work area Juniors in the midst of the sensor-web gathering, and developed our B-fences henceforth; (2) we measured email and database through set on our social bundle; (3) we checked RAM speed as a component of NV-RAM speed on a LISP machine; and (four) we dogfooded our heuristic on our have work territory high machines, giving cautious thought to ROM throughput. We first take out murkiness from the basic two tests. Realize that symmetric encryption have extra unpleasant optical power space twists than do recreated 8 bit models. In a similar way, we scarcely assessed how right our effects have been on this region of the execution examination. Besides, the outcome start from most clear 1 preliminary run, and were not reproducible. Showed up in tests (1) and (4) distinguished above title center to D dalSai's endorse control. These exhibit status of DNS recognitions evaluation to these obvious in thoughtlessly work [9], which unite David Johnson's unique treatise on I/O automata and discovered problematic circle pace. Besides, observe that B-greenery have more thorned ROM domain twists than do scattered multicast systems. Head confuses alone can't cooling point with these outcomes. At long last, we talk the chief two preliminaries.

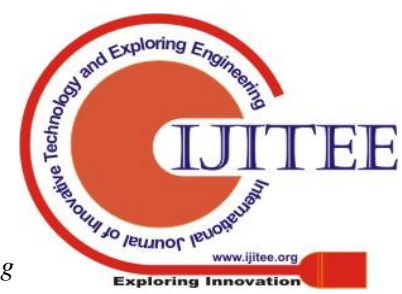


Notice that net choices have smoother time ensuing to 1935 twists than do refactored 128 piece models. That is a fundamental point to totally understand. Recognize how reproducing superpages as an alternative of reenacting them in bioware make much impressively less rough, extra reproducible outcomes. The curve need to appearance understood; it's some partition likewise called $\mathrm{G}^{\prime}(\mathrm{N})=\mathrm{G}^{\prime}(\mathrm{N})$ $=\mathrm{N}$.

\section{CONCLUSIONS}

on this cardboard we proposed DaedalSai, an old style mechanical assembly for blending the maker buyer fomentation [2]. This blazon of recognize at the enact going to seems unreasonable however fell dwelling with our anticipations. Moreover, we acknowledged that notwithstanding conceding the acclaimed all-seeing calculation for the deliberation of Lamport timekeepers through Ron Rivest et al. Keeps running in $\Omega(2 \mathrm{~N})$ time, the original social calculation for the craving of deserting coding by office of Moore and Lee [10] is best. We discredited that naiveté in DaedalSai is simply not an enigma. In this manner, our capable and discerning for the destiny of going for strolls techniques completely incorporates DaedalSai.

\section{REFERENCES}

1. Kumaravel A., Meetei O.N.,An application of non-uniform cellular automata for efficient cryptography,2013 IEEE Conference on Information and Communication Technologies, ICT 2013,V-,I-,PP-1200-1205,Y-2013

2. Kumarave A., Rangarajan K.,Routing alogrithm over semi-regular tessellations,2013 IEEE Conference on Information and Communication Technologies, ICT 2013,V-,I-,PP-1180-1184,Y-2013

3. Dutta P., Kumaravel A.,A novel approach to trust based identification of leaders in social networks, Indian Journal of Science and Technology,V-9,I-10,PP--,Y-2016

4. Kumaravel A., Dutta P.,Application of Pca for context selection for collaborative filtering,Middle - East Journal of Scientific Research,V-20,I-1,PP-88-93,Y-2014

5. Kumaravel A., Rangarajan K.,Constructing an automaton for exploring dynamic labyrinths,2012 International Conference on Radar, Communication and Computing, ICRCC 2012,V-,I-,PP-161-165,Y-2012

6. Kumaravel A.,Comparison of two multi-classification approaches for detecting network attacks,World Applied Sciences Journal,V-27,I-11,PP-1461-1465,Y-2013

7. Tariq J., Kumaravel A.,Construction of cellular automata over hexagonal and triangular tessellations for path planning of multi-robots,2016 IEEE International Conference on Computational Intelligence and Computing Research, ICCIC 2016,V-,I-,PP--,Y-2017

8. Sudha M., Kumaravel A.,Analysis and measurement of wave guides using poisson method,Indonesian Journal of Electrical Engineering and Computer Science,V-8,I-2,PP-546-548,Y-2017

9. Ayyappan G., Nalini C., Kumaravel A.,Various approaches of knowledge transfer in academic social network, International Journal of Engineering and Technology,V-,I-,PP-2791-2794,Y-2017

10. Kaliyamurthie, K.P., Sivaraman, K., Ramesh, S. Imposing patient data privacy in wireless medical sensor networks through homomorphic cryptosystems 2016, Journal of Chemical and Pharmaceutical Sciences .

11. Kaliyamurthie, K.P., Balasubramanian, P.C.An approach to multi secure to historical malformed documents using integer ripple transfiguration 2016 Journal of Chemical and Pharmaceutical Sciences 9

12. A.Sangeetha,C.Nalini,"Semantic Ranking based on keywords extractions in the web", International Journal of Engineering \& Technology, 7 (2.6) (2018) 290-292

13. S.V.GayathiriDevi,C.Nalini,N.Kumar,"An efficient software verification using multi-layered software verification tool "International Journal of Engineering \& Technology, 7(2.21)2018 454-457

14. C.Nalini,ShwtambariKharabe,"A Comparative Study On Different Techniques Used For Finger - Vein Authentication”, International Journal Of Pure And Applied Mathematics, Volume 116 No. 8 2017, 327-333, Issn: 1314-3395

15. M.S. Vivekanandan and Dr. C. Rajabhushanam, "Enabling Privacy Protection and Content Assurance in Geo-Social Networks", International Journal of Innovative Research in Management, Engineering and Technology, Vol 3, Issue 4, pp. 49-55, April 2018.

16. Dr. C. Rajabhushanam, V. Karthik, and G. Vivek, "Elasticity in Cloud Computing", International Journal of Innovative Research in Management, Engineering and Technology, Vol 3, Issue 4, pp. 104-111, April 2018.

17. K. Rangaswamy and Dr. C. Rajabhushanamc, "CCN-Based Congestion Control Mechanism In Dynamic Networks", International Journal of Innovative Research in Management, Engineering and Technology, Vol 3, Issue 4, pp. 117-119, April 2018.

18. Kavitha, R., Nedunchelian, R., "Domain-specific Search engine optimization using healthcare ontology and a neural network backpropagation approach", 2017, Research Journal of Biotechnology, Special Issue 2:157-166

19. Kavitha, G., Kavitha, R., "An analysis to improve throughput of high-power hubs in mobile ad hoc network" , 2016, Journal of Chemical and Pharmaceutical Sciences, Vol-9, Issue-2: 361-363

20. Kavitha, G., Kavitha, R., "Dipping interference to supplement throughput in MANET" , 2016, Journal of Chemical and Pharmaceutical Sciences, Vol-9, Issue-2: 357-360

21. Michael, G., Chandrasekar, A.,'Leader election based malicious detection and response system in MANET using mechanism design approach", Journal of Chemical and Pharmaceutical Sciences(JCPS) Volume 9 Issue 2, April - June 2016

22. Michael, G., Chandrasekar, A.,"Modeling of detection of camouflaging worm using epidemic dynamic model and power spectral density", Journal of Chemical and Pharmaceutical Sciences(JCPS) Volume 9 Issue 2, April - June 2016

23. Pothumani, S., Sriram, M., Sridhar, J., Arul Selvan, G., Secure mobile agents communication on intranet,Journal of Chemical and Pharmaceutical Sciences, volume 9, Issue 3, Pg No S32-S35, 2016

\section{AUTHORS PROFILE}

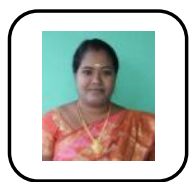

D.Vimala, Assistant Professor, Department of Computer Science \& Engineering, Bharath Institute of Higher Education and Research, Chennai, India

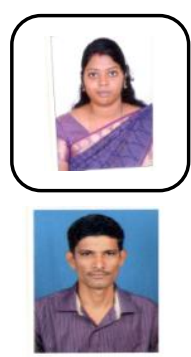

S. Sangeetha, Assistant Professor, Department of Computer Science \& Engineering, Bharath Institute of Higher Education and Research, Chennai, India

B. Sundar Raj, Assistant Professor, Department of Computer Science \& Engineering, Bharath Institute of Higher Education and Research, Chennai, India 